\title{
Criteria for the design of an educational robotics platform
}

\author{
Flor Omar ${ }^{1}$ \\ ORCID: 0000-0002-3455-5982 \\ omar.flor@udla.edu.ec \\ Universidad de las Américas \\ Facultad de Ingeniería y ciencias \\ Aplicadas \\ Quito-Ecuador \\ Toapanta Carlos ${ }^{3}$ \\ ORCID: \\ ORCID: 0000-0001-6156-5222 \\ cartoap@gmail.com \\ Universidad de las Fuerzas Armadas \\ Quito-Ecuador
}

\author{
Mauricio Fuentes ${ }^{2}$ \\ ORCID: 000-0003-4036-7280 \\ mauricio.fuentes@uce.edu.ec \\ Universidad Central del Ecuador, \\ Facultad de Ingeniería, Ingeniería en \\ Diseño Industrial. \\ Quito-Ecuador.
}

Recibido (08/08/20), Aceptado (21/08/20)

\begin{abstract}
This document explains the criteria, considerations and formulations used for the design of the main components of a mobile platform with a robotic arm. This type of robot is one of the most used in the educational field, it facilitates learning and allows the incorporation of control strategies for navigation. Aspects of resistance of materials useful for branches of engineering that lack bases on mechanics are raised.
\end{abstract}

Keywords: Design; robot; platform; educational.

\section{Criterios para el diseño de una plataforma robótica de carácter educativo}

Resumen: El presente documento explica los criterios, consideraciones y formulaciones que se emplean para el diseño de los componentes principales de una plataforma móvil con brazo robótico. Este tipo de diseños es uno de los más usados en el ámbito educativo, facilita el aprendizaje y permite la incorporación de estrategias de control para navegación. Se plantean aspectos de resistencia de materiales útiles para ramas de la ingeniería que carecen de bases sobre mecánica. Como resultados es posible destacar la obtención de las dimensiones de los elementos estructurales del robot como por ejemplo el espesor y la determinación del material más óptimo para un mejor desempeño.

Palabras Clave: Diseño mecánico, plataforma robótica, aplicaciones educativas. 


\section{I.INTRODUCTION}

Mobile robotic platforms are used at an educational level at multiple levels of university instruction, either to employ electronic techniques or to implement remote or autonomous navigation [1-4]. The field of mobile robotics is in potential development and its study is mandatory for careers related to electrical or electronic engineering. There are multiple works developed on mobile platforms [5-8], however, there are few basic design aspects related to mechanics for mobile robots and that allow adapting existing platforms in specific applications, of different capacities and situations [9].

The design of the structure of a robotic platform must consider manufacturing techniques [10], multiple geometric aspects, as well as resistance of materials [11], mechanical properties of materials and dimensioning of the main components of a mobile robot, of differential type and 4 traction wheels and with a manipulator arm with 5 degrees of freedom. It is important to consider in this design the load limitations that exist due to the geometry and weight of the robot, as well as reach lengths for the manipulation of objects taking into account the stability of the vehicle, in order to avoid possible rocking and loss of contact of the wheels with the ground [12]. In addition to this, the space must be considered to adapt the components in a convenient way and to facilitate the assembly and construction [13].

\section{II.DEVELOPING}

Developments in nanoelectronics and mechanics have allowed developments in robotics, the most general case being that of a mobile platform with a manipulator arm that allows an educational understanding of the kinematics, dynamics and control strategies of robots for the industrial field.

Continuous improvement in education models constitutes an essential challenge for teachers in order to apply and relate theory to practice in all disciplines, specifically in careers of a technical nature focused on Engineering students as well as students with engineering fundamentals. limited. Thus, a descriptive and didactic compendium of the construction of a robotic platform has been created, detailing the design of its components necessary for its proper operation in order to simplify and specify its dimensioning and construction more easily.

The study that has been carried out in this work complements the training of electronics and telematics, providing criteria, formulations, comparisons and references to execute multidisciplinary integrative projects.

\section{III.METHODOLOGY}

\section{A.Design considerations}

The robotic platform [1] with a manipulator arm to be assembled, must first consider a material that supports the distributed loads that the P1 plate must carry. The length $\mathrm{L}$ depends largely on the size of the wheels to be used. To determine the diameter $\mathrm{D}$ of the wheel, the engine speed [14] must be considered, since a large wheel will make the vehicle move faster, however, it will reduce the effect of the engine torque applied to each wheel $[15]$. Another consideration is the size of the terrain variations. If the terrain is perfectly flat, a small wheel may be convenient to take advantage of a greater torque from the motor. In practice, this diameter can be associated as a function of the maximum speed required to be achieved and the speed of the motor.

$$
\frac{D}{2}=\frac{V}{\omega}
$$

Where, $\mathrm{D}$ is the diameter, $\mathrm{V}$ is the velocity and $\boldsymbol{\omega}$ is the angular velocity.

The speed in (1) linear of a platform [16], works properly with speeds lower than $50 \mathrm{~cm} / \mathrm{s}$. The wheelbase is considered sufficient to house the proper motors to move the robotic platform. The width of the wheel tw, is an important parameter in the driving of the mobile robot [17] and should promote good stability to the robot, 
and due to its weight, the contact area with the ground should be increased. The motor required to move the platform will be a function of the total weight of the robot plus the load and a safety factor, such that the following expression is fulfilled.

$$
T=\frac{D}{2} F r
$$

Where, $\mathrm{T}$ is the torque, $\mathrm{D}$ is the diameter and $\mathrm{Fr}$ is the friction force

$$
F r=k \frac{*(q A+p b r a z o+p p i n z a)}{4}
$$

Where, $\mathrm{Fr}$ is the friction force, $(\mathrm{qA}+\mathrm{p}$ arm $+\mathrm{p}$ clamp) is the sum of distributed loads applied to the robot wheels. In (2), the torque is presented as a function of the friction force and this, in turn, in (3), as a function of the friction coefficient $k$ and the weight of the complete robot, whose force is considered equally distributed in the 4 wheel drive differential [17].

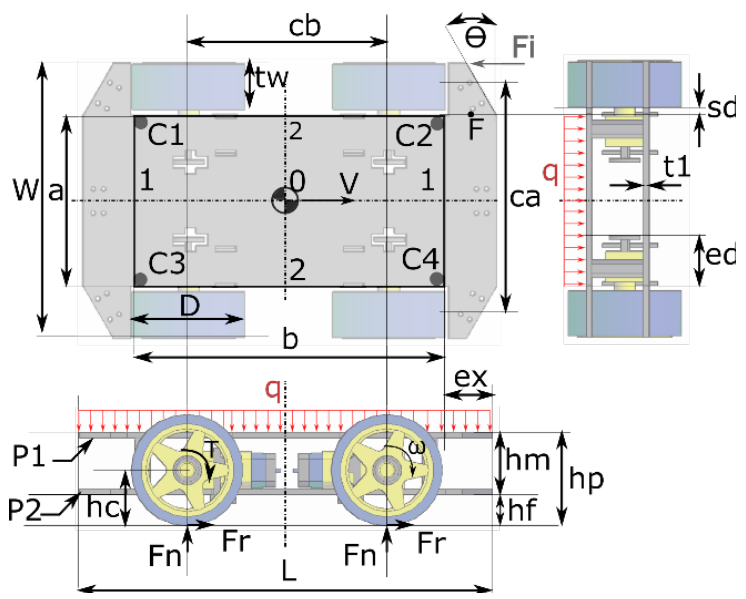

Fig 1. Geometric parameters for the robotic platform design.

Regarding the plates that form the chassis $\mathrm{P}_{1}$ and $\mathrm{P} 2$ (Fig. 1), these must carry the load of the rest of the robot that will be distributed appropriately. The greatest load will be supported by plate P1 and the load of robot components and load to be transported in a distributed manner q on the surface of $\mathrm{P} 1$ will be considered by applying the distributed load q on plate $\mathrm{P} 1$. The $\mathrm{P} 2$ plate provides rigidity to the structure of the vehicle chassis and allows fastening for the motors and encoders. The plate $\mathrm{P} 1$ will support more load than the plate $\mathrm{P} 2$ and its analysis considers the case of a plate supported at its corners $\mathrm{C} 1-\mathrm{C} 4$. According to [18], the maximum moment will be found along axis 1-1 with its maximum value at point 0 .

$$
M_{2}=\alpha_{2} q b^{2}
$$

The parameter $\alpha 2$ is obtained from table I, according to reference [18], for which the relationship of the dimensions a and b, (4) must be considered. 
TABLE 1. GEOMETRIC PARAMETERS $\alpha$

\begin{tabular}{|c|r|r|r|r|}
\hline $\mathrm{a} / \mathrm{b}$ & $\boldsymbol{\alpha}_{\mathbf{0}(\boldsymbol{a})}$ & $\boldsymbol{\alpha}_{\mathbf{0}(\boldsymbol{a})}$ & $\boldsymbol{\alpha}_{\mathbf{0}(\boldsymbol{a})}$ & $\boldsymbol{\alpha}_{\mathbf{0}(\boldsymbol{a})}$ \\
\hline 1.0 & 0. & 0. & 0 & 0 \\
& 0947 & 0947 & .160 & .160 \\
& & & 6 & 6 \\
\hline 0.9 & 0. & 0. & 0 & 0 \\
& 0689 & 1016 & .136 & .154 \\
& & & \multicolumn{1}{c|}{7} & 1 \\
\hline 0.8 & 0. & 0. & 0 & 0 \\
& 0047 & 1078 & .114 & .148 \\
& & & 8 & 6 \\
\hline 0.7 & 0. & 0. & 0 & 0 \\
& 0289 & 1132 & .095 & .143 \\
& & & 5 & 5 \\
\hline 0.6 & 0. & 0. & 0 & 0 \\
& 0131 & 1178 & .076 & .138 \\
& & & 9 & 6 \\
\hline 0.5 & 0. & 0. & 0 & 0 \\
& 0005 & 1214 & .059 & .133 \\
& & & 2 & 9 \\
\hline
\end{tabular}

If $\mathrm{P} 1$ has a larger geometry and with more details than the area delimited with sides a and b, the latter will be suitable for the consideration of resistance since it is the region that will be most loaded and that allows a more realistic determination of resistance behavior. In order to verify the material and the thickness t 1 of the plate $\mathrm{P} 1$, the bending stress of the plate is evaluated, considering the direction of greater bending through the following expression.

$$
\sigma_{F}=\frac{M_{2} y}{I}
$$

Where $\sigma \_F$ is the bending stress to which the plate is subjected, $M \_2$ is the greatest moment with respect to the central section of the plate, that is, M_2, and is the distance from the center of gravity of the cross section towards the critical fiber. I is the inertia of the cross section of the material with respect to its center of gravity and considering that its height will correspond to the thickness of the material t1, (5).

In figure 1, the distance hf should be the minimum enough so that, given the unevenness of the ground or the presence of foreign elements, the mobile robot is not stranded. The height $\mathrm{hm}$ will facilitate the incorporation of the 4 DC motors that will move each of the robot's wheels, which will be fixed on the plate P2 and below P1, A safety distance ex is required to avoid elements of considerable size, may collide with the wheels directly. The chamfer where the angle $\theta$ is specified, will prevent the robot from being immobile in a corner, allowing it to maneuver in closed spaces without getting stuck in corners of the environment. The minimum distance ex must withstand the impact of the vehicle traveling at its maximum speed [19] and whose moment with respect to point $\mathrm{F}$ is carried out by force Fi. Using (5).

A safety distance sd between the plate P1 and the wheels, will allow a better mobility without them getting stuck with P1. Distances greater than $6 \mathrm{~mm}$ are recommended. The distance ed, when installing the motors, must not exceed a / 2 . 


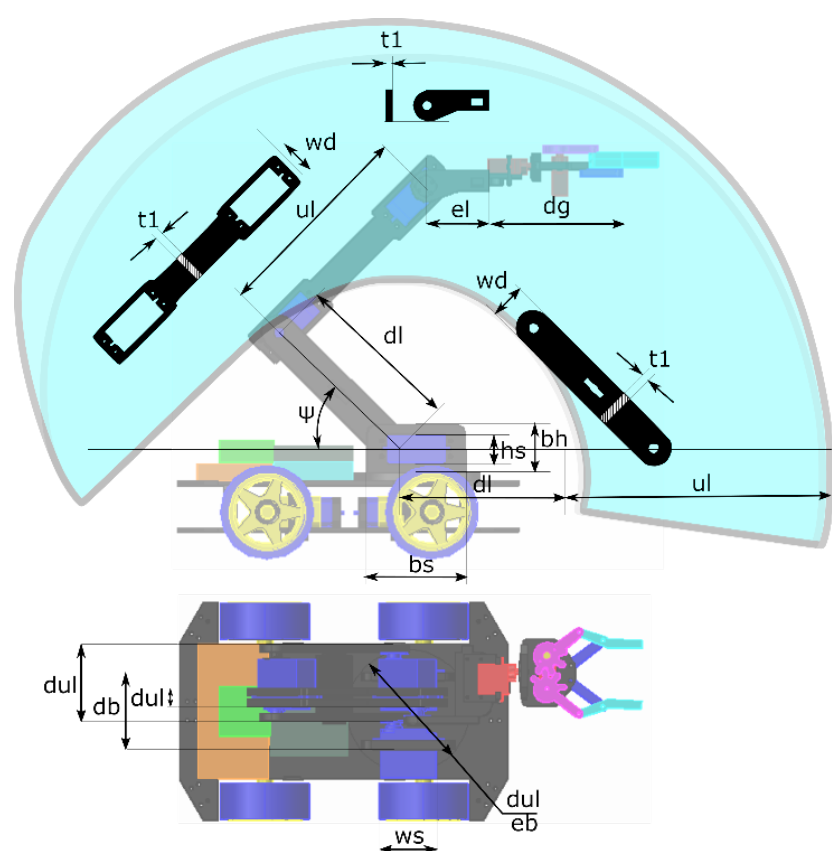

Fig 2. Parameters for the manipulator arm design

Figure 2 presents the dimensional parameters that are taken into account for the design of the manipulator arm, the same ones that consider static loads given that the arm will not exceed the linear speed of $1.2 \mathrm{~m} / \mathrm{s}$ at the end of the manipulator, avoiding an unnecessarily dynamic analysis. for this efects.

The components of the manipulator arm structure will have thicknesses $\mathrm{t} 1$ similar to those of the components $\mathrm{P} 1$ and $\mathrm{P} 2$.

In figure 2, the height bh and width bs of the servomotor supports at the base of the manipulator arm must consider an opening of dimensions hs and ws depending on the servomotor used. The recommended distance from the hole to the edges can be determined based on the torque of the servomotors. The distance $\mathrm{dl}$ and ul should preferably be equal if the intention is to give the manipulator a greater range. The lengths $\mathrm{dl}$, ul, el and dg, should allow the manipulator arm, in the retracted position and described with an angle $\psi$ of $45^{\circ}$, to locate its center of gravity between the driving wheels to provide better stabilization and reduce the rocking of the vehicle moving with load. To allow displacement with load and arm retracted, the moments generated by the weight of the arm with its components and acting on the platform applying WA at a distance LR, must provide more moment than that provided by the gripper and the load PC sustained with a distance LS, with respect to the CR point of the front wheel, as shown in figure 3.

The securing of elements remotely will transmit a moment that could overturn the platform, therefore, the load to be secured should be considered a function of the estimated weight of the robot. The maximum extension of the manipulator arm is illustrated in figure 3. In it, the load PL corresponds to the load that the gripper will hold, WA is the load generated by the weight of the arm and gripper at a distance RD from the center of rotation and that corresponds to the distance LA minus the radius of the wheel D / 2 . The load PL corresponds to the weight of the mobile platform plus the servos that move the elements of the lower link of the manipulator and is located at a distance LD from the center of rotation CR of the front wheel.

$$
[(\mathrm{WA} * \mathrm{RD})+(\mathrm{PC} * \mathrm{LL})] \mathrm{FS}=\mathrm{PL} * \mathrm{LD}
$$

The FS value presents a safety factor to guarantee traction on the wheels in case of movement with load and for the case presented in figure 3. The design presented and composed of three fundamental parts, mobile platform, manipulator arm and gripper, if manufactured from the same material thickness, will present approximate referen- 
ce weights in percentage values of $82 \%$ for the mobile platform with the control components of the whole robot; $12 \%$ the weight of the manipulator arm without considering the two lower servos and anchored to the mobile platform; $6 \%$ for the chuck with all its servomotors. The payload can be estimated using (7).

$$
P C=\frac{W_{\text {plat }} L D-W_{\text {arm }} R D}{2 L L * F S C}
$$

The value obtained in $\mathrm{PC}$ will correspond to the mass that the robot will be able to lift without affecting the traction of the wheels with the ground, for whose determination an FSC safety factor for the load is considered (7).

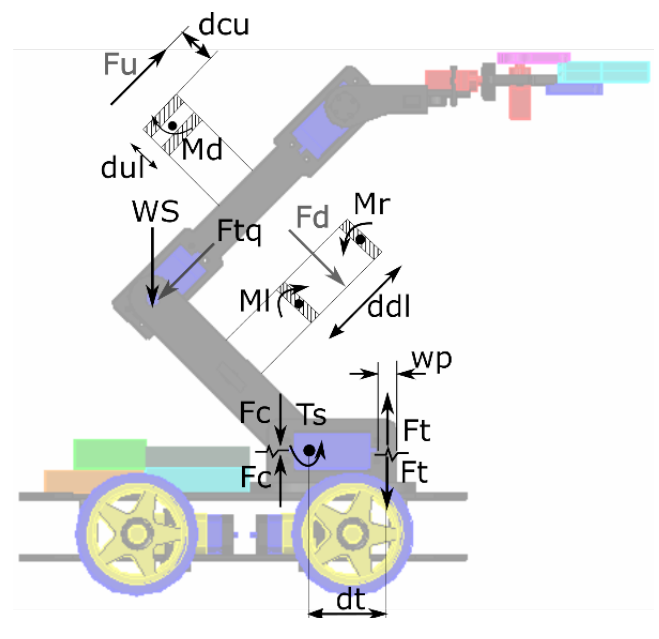

Fig 4. Parameters for the resistance in the structure of the manipulator arm.

In figure 4, One of the critical points in the design is the union of the manipulator arm with the mobile platform and specifically the bases that hold said servomotors. Adequate torques must be chosen to properly and safely move the PC load. The design contemplates a support for two servomotors, used to move the first link of the robot made up of two parallel bars of length $\mathrm{dl}$ and separated by a distance ddl. Two servomotors are necessary in the base since it is where greater moment is required. Each of these actuators transmits a moment Ts in the support of the base, generating a traction force Ft on the element and a compression force Fc on the other side. Since the side subjected to compression does not have a length that gives the failure buckling, like a column; the most prone failure in these cases is traction, so this force can be determined by:

$$
\frac{\sigma_{t b}}{f s t}=\frac{T s / d t}{t 1 * w p}
$$

In (8), a section with a minimum area formed by $\mathrm{t} 1$ and wp should be chosen that allow $\sigma$ tb to be less than the resistance of the material, considering a safety factor fst, recommended equal to or greater than 2 . In figure 4 , the distance ddl at which the elements of the first link of the robot are separated should be considered such that it provides rigidity to the structure and prevents buckling of both components. Considering the maximum torque load of the servomotors and the weight of the upper link, clamp and load object, a critical load case can be considered in which the force of the weight of the upper elements WS and the force of the torque Ftq, contribute their maximum magnitudes thus applying a force Fd applying moments to the two bars due to the incidence of the centered load 
and weight of upper elements. The torsion in each element can be analyzed using (9).

$$
\frac{\tau}{\text { fstor }}=\frac{T L}{G \theta}
$$

In (9), the torque represented by J, represents the shear stress of the material, this considers a safety factor fstor whose value must be greater than or similar to 2 , the torque obtained by the force Fd and the distance $\mathrm{ddl} / 2$. The parameter $\mathrm{L}$ of (9) represents the length that for the analyzed case will be equal to $\mathrm{dl}$. The value for $\mathrm{G}$ corresponds to the value of the transverse modulus of elasticity, a characteristic property of the material used, and $\omega$ corresponds to the value of the angular displacement.

A maximum angular displacement $\omega$ max should be considered, such that the stress $\tau$ does not exceed the shear strength value of the material. For the case of the upper elements, the load Fu has a lateral displacement a distance $\mathrm{dcu}$, therefore, it transmits a torque with respect to the geometric center of the cross section of the elements of the second link of the robotic arm and of lengths ul. Equation 9 can be used to limit the angle displaced by the effect of the load and the elements of the displaced clamp Fu, which will apply a moment Md forcing the structure to rotate an angle $\theta$, values must be found that confirm that the stress $\tau$ is less than the resistance of the material used. Regarding the gripper and given that the load to be transported will be reduced and depending on the weight of the robot, the mechanical requirement is not a relevant aspect for the few grams that will be held in the mechanism.

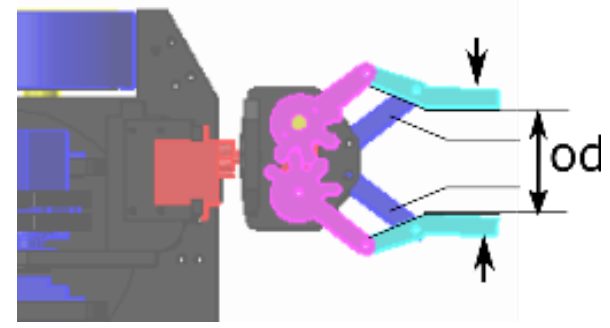

Fig 5. Parallel motion gripper mechanism.

Figure 5 shows a model of a clamping clamp with parallel movement. This movement facilitates the work in structured environments and with multiple geometry frames whose external dimensions are less than the distance or $\mathrm{d}$ minus a margin that allows the operation and manipulation of the piece and that in practice can give good benefits.

\section{B.Materials}

For the selection of materials, the methodology defined by Michael Ashby [20] is followed, in which the robot is divided into each of its components, and for each of these components the design requirements expressed as functions, restrictions and objectives are defined. . All materials are initially considered candidates for use in components. Restrictions are used to eliminate non-compliant materials, decreasing the number of eligible options; for example, if resistance to corrosion in water is required, materials that do not meet this restriction are initially removed. The component function is used to define a material index that optimizes performance, for this, material selection letters and index selection tables are used, which allow defining a new list of materials that meet the initial restrictions and optimize the index of performance, as an example a reduced table is presented with different indices that consider a design limited by the resistance to minimum mass, according to the function of the product and considering its yield stress $\sigma_{-}$f and the density $\rho$, see table 2 . 
Table 2. Material selection indexes for design limited by resistance to minimum mass.

\begin{tabular}{|c|c|}
\hline Role and restrictions & Index (Maximize) \\
\hline $\begin{array}{l}\text { Tensile element } \\
\text { Stiffness and specified } \\
\text { length, free section a rea }\end{array}$ & $\sigma_{f} / \rho$ \\
\hline $\begin{array}{l}\text { Torsionally loaded shaft } \\
\text { Load, length, specified } \\
\text { shape; free section a rea }\end{array}$ & $\sigma_{f}^{2 / 3} / \rho$ \\
\hline $\begin{array}{l}\text { Beam loaded in bending } \\
\text { Load, length, specified } \\
\text { shape; free section a rea }\end{array}$ & $\sigma_{f}^{2 / 3} / \rho$ \\
\hline $\begin{array}{l}\text { Compression column } \\
\text { Load, length, specified } \\
\text { shape; free section a rea }\end{array}$ & $\sigma_{f} / \rho$ \\
\hline $\begin{array}{l}\text { Flex-loaded flat panel } \\
\text { Specified stiffness, length } \\
\text { and thickness; free } \\
\text { thickness }\end{array}$ & $\sigma_{f}^{1 / 2} / \rho$ \\
\hline
\end{tabular}

To meet the objectives, with the materials that meet the restrictions, they are classified based on the index and the advantages, disadvantages and uses of the material are reviewed in the technical literature, with which the appropriate material is finally chosen.

As an example, the material selection process for plates $\mathrm{P}_{1}$ and $\mathrm{P} 2$ is presented below.

Function: Support the loads of the component weights, it works like a flex plate.

Restrictions: Machinable, to screw the components

Free variables: Thickness

Objectives: Minimum weight, in order to optimize the weight of the robot and the duration of the battery

Performance index: which is used for design limited by the resistance to minimum weight for a flexural plate:

$$
M=\frac{\sigma_{f}^{1 / 2}}{\rho}
$$




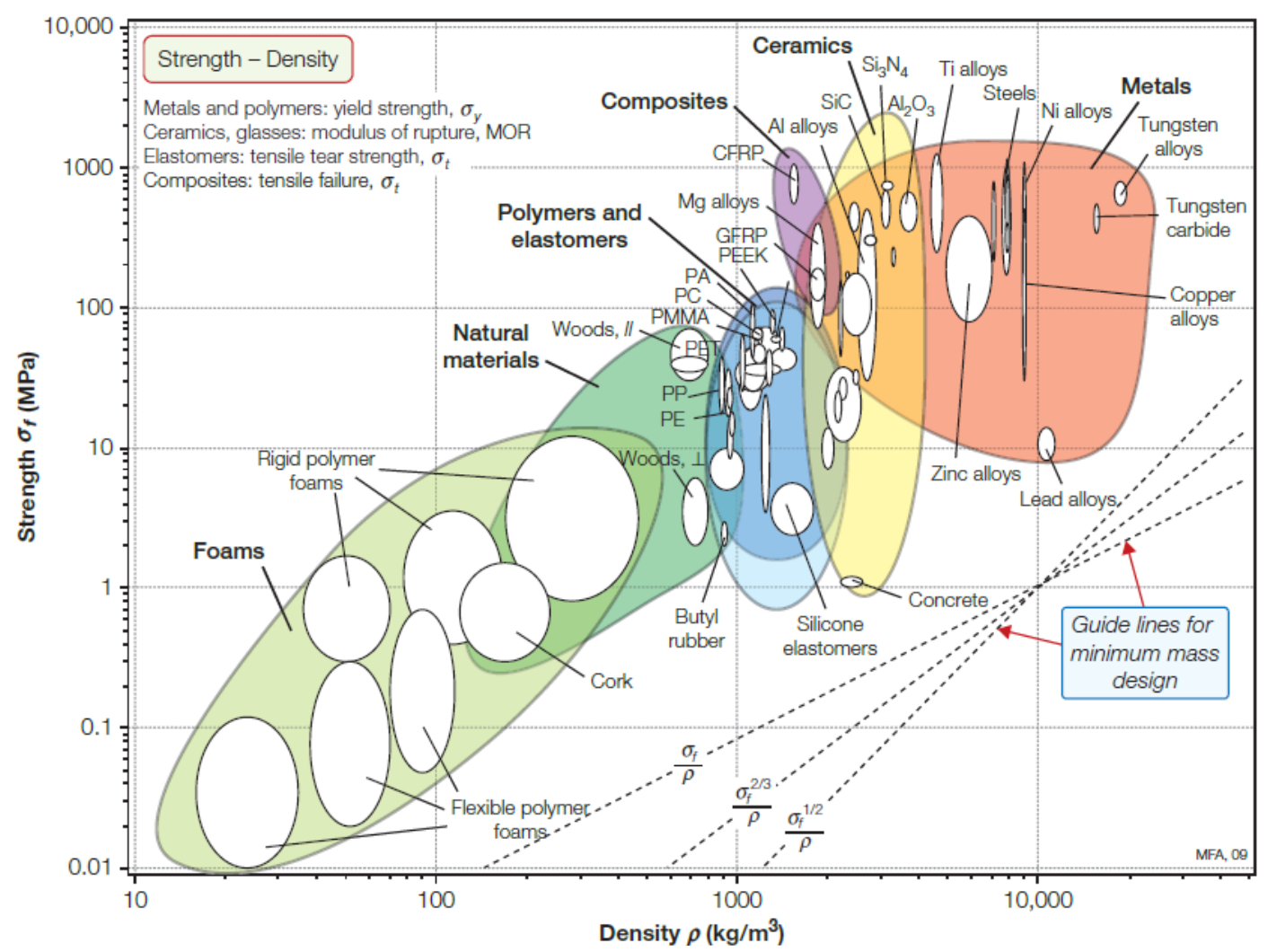

Fig 6. Methodology for selection of materials [20]

Where $\sigma \_f$ is the yield strength or maximum resistance of the material and $r$ is the density of the material. A letter of materials is chosen, which contains in its axes the variables of the performance index, see figure 6 . Then the line with the inclination corresponding to the selection index $\frac{\sigma_{\rho}^{1 / 2}}{\rho}$, see line blue in figure. In this case, it is planned to maximize the index, since the platform must have high resistance and low weight, so materials with the value of this high index must be chosen. The line is transported until there are few materials that meet the value of the high index, see selection area in green. Next, a table is made with the materials that are on the line and the material index is calculated and its suitability to the design is critically analyzed, as shown in table III, Where the suitable material was carbon fiber.

Table 3. Final materials after the selection process and selection index.

\begin{tabular}{|l|l|l|l|l|}
\hline Material & $\begin{array}{l}\sigma_{f} \\
(\mathrm{MPa})\end{array}$ & $\begin{array}{l}\rho \\
\left(\mathrm{kg} / \mathrm{m}^{3}\right)\end{array}$ & $\frac{\sigma_{f}^{1 / 2}}{\rho}\left(\frac{\mathrm{MPa}^{1 / 2}}{\mathrm{~kg} / \mathrm{m}^{3}}\right)$ & Observations \\
\hline $\begin{array}{l}\text { Rigid polymer } \\
\text { foam }\end{array}$ & 7.00 & 200 & 0.013 & $\begin{array}{l}\text { Light ma terial, but you could see problems holding the } \\
\text { elements }\end{array}$ \\
\hline Wood & 80.0 & 7.50 & 0.011 & $\begin{array}{l}\text { Suitable mate rial, but could have problems with } \\
\text { weather conditions }\end{array}$ \\
\hline $\begin{array}{l}\text { Carbon fiber } \\
\text { reinforced } \\
\text { polymer matrix } \\
\text { composite }\end{array}$ & 900 & 1800 & 0.016 & $\begin{array}{l}\text { The one with the best strength / density ratio, if price } \\
\text { is not important it would be the right material. }\end{array}$ \\
\hline
\end{tabular}

More material selection cards and more restrictions can be used, depending on each product function. 


\section{IV.RESULTS}

The mechanical design of the mobile robot in this document is presented in figure $7.3 \mathrm{~mm}$ thick polymethyl-methacrylate (PMMA) acrylic has been used for the manufacture of the structural parts and the aspects presented in the previous section have been considered to validate and adjust the design, allowing it to be functional and suitable for academic teaching aspects.

The structure designed based on the criteria of resistance of materials and depending on the forces and loads applied allows proper sizing and guarantees the rigidity of the mobile lower part and the manipulator arm.

The designed and assembled platform presents small deflections less than $0.1 \mathrm{~mm}$, ease of assembly for the proposed configuration, speed of manufacturing parts from the selected processes and the feasibility of being dimensioned according to the transport payload q (Figure 1).

The double links that make up the manipulator arm represented in figure 2 have an adequate behavior to torsion and bending, even for the most critical position as long as the payload PC does not overturn the entire robotic platform. Figure 7 represents the result of the verified design that meets all the criteria of the previous sections.

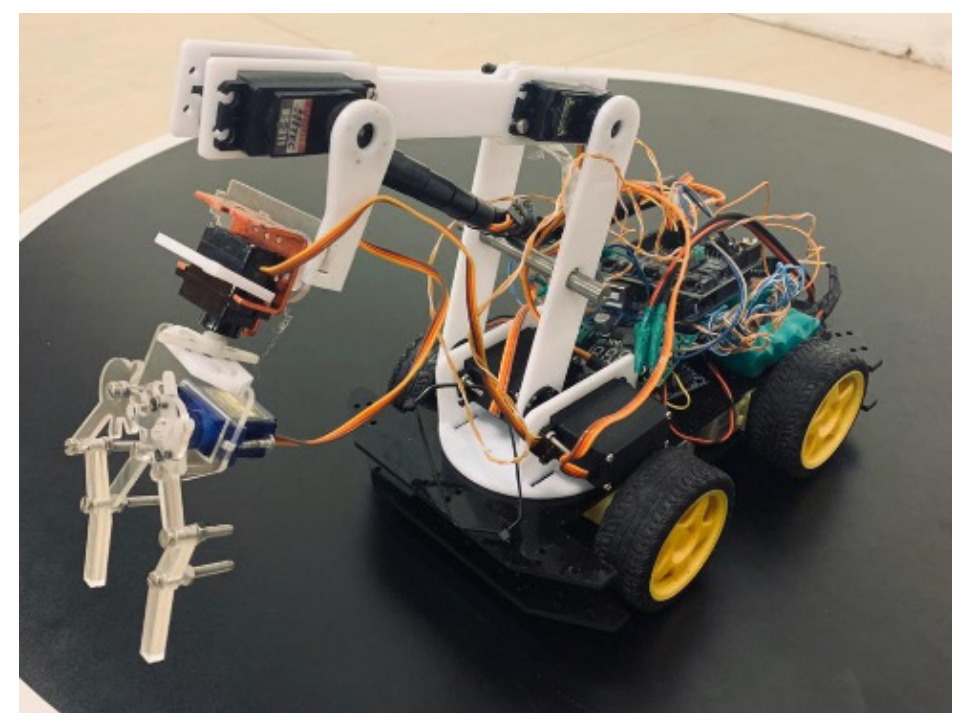

Fig 7. Robotic platform built

\section{V.CONCLUSIONS}

The design of an academic robotic platform uses multiple material mechanics criteria, relating parameters and static loads to select dimensions based on their strength as a fundamental parameter for the design. The design aspects presented, allow adapting and proposing designs adapted to multiple load situations and ground conditions, some geometric aspects also consider characteristics of the motors and utility distances for a basic design of the components that support greater loads in the operation of a mobile robotic platform with a manipulator arm. The present work can be proposed as a learning activity at initial levels of electronic engineering in order to acquire fundamentals about mechanics of materials and thus enrich their knowledge by extending it to multiple possibilities. The platform obtained allows the incorporation of control strategies, remote operation and autonomous navigation, it also offers stability in the transfer of cargo, which is a function of the weight and morphology of the robot.

\section{RECOGNITION}

W e appreciate the participation of students of the Mechatronics engineering career of the International University of Ecuador and those of the Industrial Engineering career of the University of the Americas, who motivated the completion of this document, their doubts have served to create a guide useful, a contribution to 
the educational environment of future generations.

\section{REFERENCES}

[1]O. Flor, W. Hernandez, O. Vargas, A. Mendez, O. Sergiyenko and V. Tyrsa, "Construction of a Robotic Platform of Differential Type for First-Year Students of Electronic Engineering", International Symposium on Power Electronics, Electrical Drives, Automation and Motion (SPEEDAM), Sorrento, Italy, 2020, pp. 538-543, doi: 10.1109/SPEEDAM48782.2020.9161870.

[2]O. Flor, "Building a mobile robot", Education for the future, 2020 [Online] Available: https://omarflor2014. wixsite.com/misitio

[3]A. Ollero, "ROBÓTICA: Manipuladores y robots móviles, Marcombo Boixareu Editores, 2001, Chapters 1-2 (pp. 1-37), Chapter 4 (pp. 85-87), Chapter 9 (pp. 258-267), and Chapter 10 (pp. 303-327).

[4]K. Pitti, L. Muñoz, I. Moreno, J. Serracín, "La robótica educativa, una herramienta para la enseñanza-aprendizaje de las ciencias y tecnologías”, Researchgate, pp. 74-90, 2012.

[5]E. Ruiz, R. Acuña, N. Certad, A. Terrones and M. E. Cabrera, "Development of a Control Platform for the Mobile Robot Roomba Using ROS and a Kinect Sensor", 2013 Latin American Robotics Symposium and Competition, Arequipa, 2013, pp. 55-60.

doi: 10.1109/LARS.2013.57J.

[6]J. Wu, C. Lv, L. Zhao, R. Li and G. Wang, "Design and implementation of an omnidirectional mobile robot platform with unified I/O interfaces," 2017 IEEE International Conference on Mechatronics and Automation (ICMA), Takamatsu, 2017, pp. 410-415.

doi: 10.1109/ICMA.2017.8015852

[7]M. Ali, W. Yusoff, Z. Hamedon, M. Yussof and M. Mailah, Mechatronic design and development of an autonomous mobile robotics system for road marks painting, IEEE Industrial Electronics and Applications Conference, 2016, pp. 336-341, doi: 10.1109/IEACON.2016.8067401

[8]H. Guo , K. Su , K. Hsia , and J. Wang , Development of the mobile robot with a robot arm, Proceedings IEEE International Conference on Industrial Technology (ICIT), Taipei, Taiwan, 2016, pp. 1648-1653.

[9]R. A. Orozco-Velázquez et al., Ackerman Mobile Robot with Arm,International Conference on Mechatronics, Electronics and Automotive Engineering (ICMEAE), Cuernavaca, 2016, pp. 55-60, doi: 10.1109/ICMEAE.2016.019.

[10]A. Razak et al., Mobile robot structure design, modeling and simulation for confined space application, 2nd IEEE International Symposium on Robotics and Manufacturing Automation (ROMA), 2016 Ipoh, 2016, pp. 1-5. doi: 10.1109/ROMA.2016.7847808

[11]G. Evangelista, "Design and modeling of a mobile research platform based on hexapod robot with embedded system and interactive control," 2014 19th International Conference on Methods and Models in Automation and Robotics (MMAR), Miedzyzdroje, 2014, pp. 294-299.

doi: 10.1 109/MMAR.2014.6957367

[12]Y. Qu, R. Liu and B. Li, "Mechanical design, modeling and analysis of a miniature throw-able robot with transformation capacity," 2012 IEEE International Conference on Robotics and Biomimetics (ROBIO), Guangzhou, 2012, pp. 2294-2299.

doi: $10.1109 /$ ROBIO.2012.6491311

[13]M. Maldonado, J. Cerezo, J. Aguayo, "Diseño y Construcción de un Brazo Robótico Manipulador Móvil," Sexto Coloquio Interdisciplinario de Doctorado - Universidad Popular Autónoma del Estado de Puebla, 2013.

[14]Friendsofbest.org, (2020). [Online]. Available: http://www.friendsofbest.org/wp-content/ uploads/2014/03/Optimizing-Robot-Wheel\%C2\%AoDiameter.pdf. [Accessed: 28- Jan- 2020].

[15]"Modelación de un Robot Móvil de Dos Ruedas con Tracción Diferencial," $8^{\circ}$ Congreso Nacional de Mecatrónica Noviembre 26 y 27, 2009. Veracruz, Veracruz.

[16]K. Csorba, D. Varga , G. Tevesz, I. Vajk, The RobonAUT Autonomous Mobile Robot Construction Contest, Proceedings of the 9th IFAC Symposium Advances in Control, 2012

[17]H. Ming, S. Bao-Long, C. Wen-Hua, H. Dan-Min, L. De-Bei and H. Ya-Di, "Structure synthesis \& configuration transformation of variable topology repeated foldable wheel," 2013 IEEE International Conference on Robotics and Biomimetics (ROBIO), Shenzhen, 2013, pp. 85-90.

doi: $10.1109 /$ ROBIO.2013.6739440 
[18]Plate Supported On All Corners With Uniform Load, Structx.com, (2020). [Online]. Available: https:// structx.com/Plate_Formulas_014.html. [Accessed: 28- Jan- 2020].

[19]G. Alvarez, O. Flor, "Desempeño en métodos de navegación autónoma para robots móviles," Revista Minerva de Investigacion, pp. 19-29.

[20]M. F. Ashby, "Materials Selection in Mechanical Design," Third edition, Oxford, 1992.

\section{CURRICULUM SUMMARY}
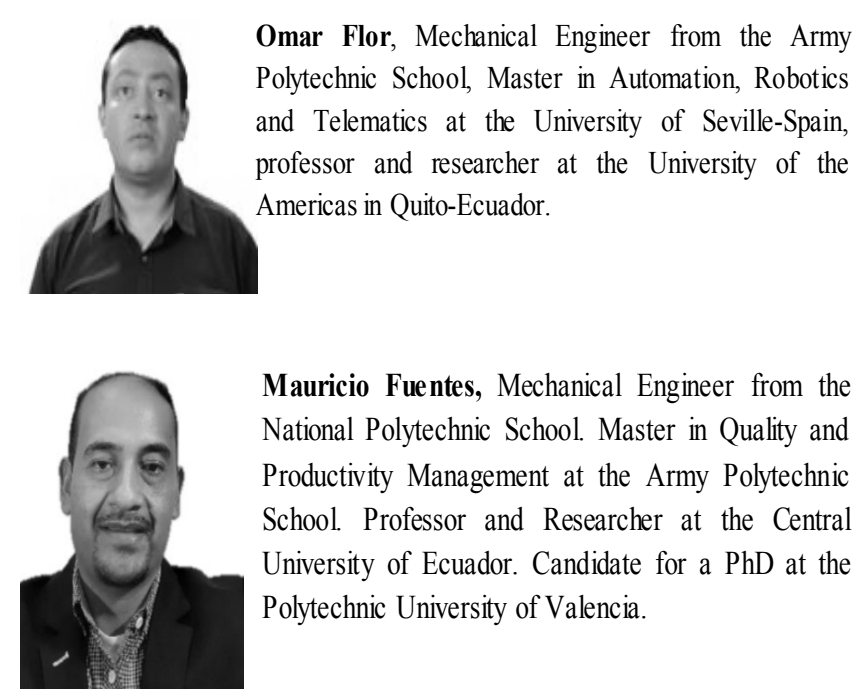

Mauricio Fuentes, Mechanical Engineer from the National Polytechnic School. Master in Quality and Productivity Management at the Army Polytechnic School. Professor and Researcher at the Central University of Ecuador. Candidate for a $\mathrm{PhD}$ at the Polytechnic University of Valencia.

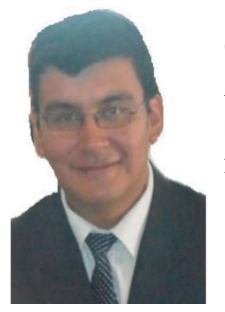

Carlos Toapanta, Mechanical Engineer from the Army Polytechnic School, experience in design, supervision, and quality assurance and control in the manufacturing and oil industry 